\title{
OBSERVATIONS ON THE REPRODUCTION OF THE GIANT COCKROACH, BLABERUS CRANIIFERA BURM.
}

\author{
By W. L. NutTing \\ Biological Laboratories, Harvard University
}

In his Embryology of the Viviparous Insects, H. R. Hagan (1951) cites nine species of roaches recorded as exhibiting some type of viviparity, or oviparity approaching viviparity. Chopard (1950) and Van Wyk (1952) have furnished two additional examples of viviparous blattids. Much of the evidence for viviparity has been indirect; that is, it has been based on dissections of gravid females, while in scarcely half the cases has the birth process actually been witnessed. Among the species mentioned by Hagan are the West Indian Blabera fusca Brunner (Saupe, 1929), and a Bolivian Blabera species (Holmgren, 1903). (Blabera fusca Brunner can probably be referred to craniifera Burm. according to Rehn and Hebard (1927).) Over the past seven years I have had the opportunity to observe rather closely a flourishing culture of Blaberus craniifera Burm., originally started from Florida specimens by Prof. C. T. Brues. (This roach is limited to Cuba in the West Indies and ranges from southern Mexico to British Honduras on the mainland; it has undoubtedly been introduced to Key West from Cuba.) During this period I have found newly hatched nymphs dozens of times, but only recently have I observed parturition itself. Before recounting this event, it seems appropriate to include available information on mating, the little-known spermatophore, and other relevant details on the reproductive habits of this large laboratory roach.

Blaberus is rarely active during the daytime, even in the laboratory, and I have never seen courting behavior. However, Saupe (1929) described the one case of love play and copulation for B. fusca which he observed during daylight. The actions were generally much like those detailed for 
some of the more common roaches (see Roth, 1952), except that no dorsal glands are known which attract and engage the female as in Blattella. The male vibrates his antennae and goes through brisk quivering motions, sometimes raised up on his legs. After contact stimuli from the interested female he raises his wings, while the female advances over his abdomen as far as his raised wings to the "female superior pose". As the male makes contact with the female's genitalia, they simultaneously turn in opposite directions to complete copulation in the "false-linear position" which is typical for the roaches. The pair observed by Saupe remained together for 80 minutes, but I have noted many pairs together for four hours and more which is much longer than is usual for most roaches.

Many texts list the occurrence of spermatophores in certain members of the Thysanura, Odonata, Neuroptera, Lepidoptera, Coleoptera, and several subgroups of the Orthoptera. Until recently, oddly enough, it was not generally known that this method of sperm transfer is also used by at least some of the blattids. Zabinski (1933) first described and figured the spermatophore for Blatta orientalis, while Qadri (1938) reported some conflicting observations on spermatophore formation for the same species. Hagan (1941) mentioned the genital pouch as a receptacle for the spermatophore in Diploptera, but did not describe it. The spermatophore of Periplaneta americana was described and figured in position by Gupta (1947). The formation of the spermatophore of Blattella germanica is described and discussed by Khalifa (1950). Roth (1952) presented notes on the spermatophores of Blattella, Blatta, and Periplaneta. Recently Van Wyk (1952) described the spermatophore of Leucophaea maderae. The present observations on Blaberus now make a total of five subgroups of the Blattaria which are known to form spermatophores. This strengthens Khalifa's presumption that spermatophores are of general occurrence among the roaches.

Figs. 1 and 2 show the position of the spermatophore (Sph) in Blaberus shortly after copulation. The freshly deposited spermatophore is a tailed, pearly-white spheroid, about $3.5 \mathrm{~mm}$. in diameter. A clear, jelly-like mass fills 
the vestibule (Ve) and cements (stippled area) the spermatophore into the genital pouch. According to Qadri the spermatophore of Blatta contains a number of sperm capsules, while Khalifa and Van Wyk described two sperm sacs in those of Blattella and Leucophaea. In Blaberus the spermatophore is irregularly divided into a small and a large compartment, while two sperm ducts lead from the larger one to oppose the spermathecal orifices. Whereas most of the roaches previously noted have not retained their spermatophores longer than 24 hours before dropping them, one Blaberus female was noted to retain her spermatophore intact for five days, when on the sixth day a mass of chalky fragments and greyish jelly was observed in her genital pouch.

As in the other roaches which retain their eggs for a considerable time, the oötheca resembles a thin, transparent plastic bag drawn tightly about the eggs. It is quite smooth and, as it varies in thickness, a dull ochreaceous to a bright chestnut in color. A point which has previously been overlooked in Blaberus is that the oötheca is not complete, so that the micropylar end of each egg is plainly visible through a slit usually wider than one egg. The extremely delicate oötheca of Diploptera as described by Hagan, never covers more than half of each oöcyte, and may not even cover the older eggs. Although Blaberus does not approach this extreme, the pro- and mesothorax of each embryo are virtually free of the oötheca shortly before birth. This open type of oötheca may be of some importance to embryonic respiration within the brood pouch as suggested by Hagan. The elaborate arrangement of air tubes through the keel of the conventional armored roach oötheca (Lawson, 1951)

Explanation of Plate 1

Fig. 1. Blaberus craniifera Burm. Ventral dissection of female reproductive system showing spermatophore (Sph) cemented (stippled area) into the genital pouch over the gonopore. The posterior ventral wall of the genital chamber has been removed. Fig. 2. Sagittal section through region shown in Fig. 1. AG, accessory gland; An, anus; BrS, brood sac; C, colon; Od, oviduct; Ov, ovary; Ovp, ovipositor; R, rectum; $\mathrm{S}$, sternite; Sph, spermatophore; T, tergite; Ve, vestibule; Vul, vulva. 

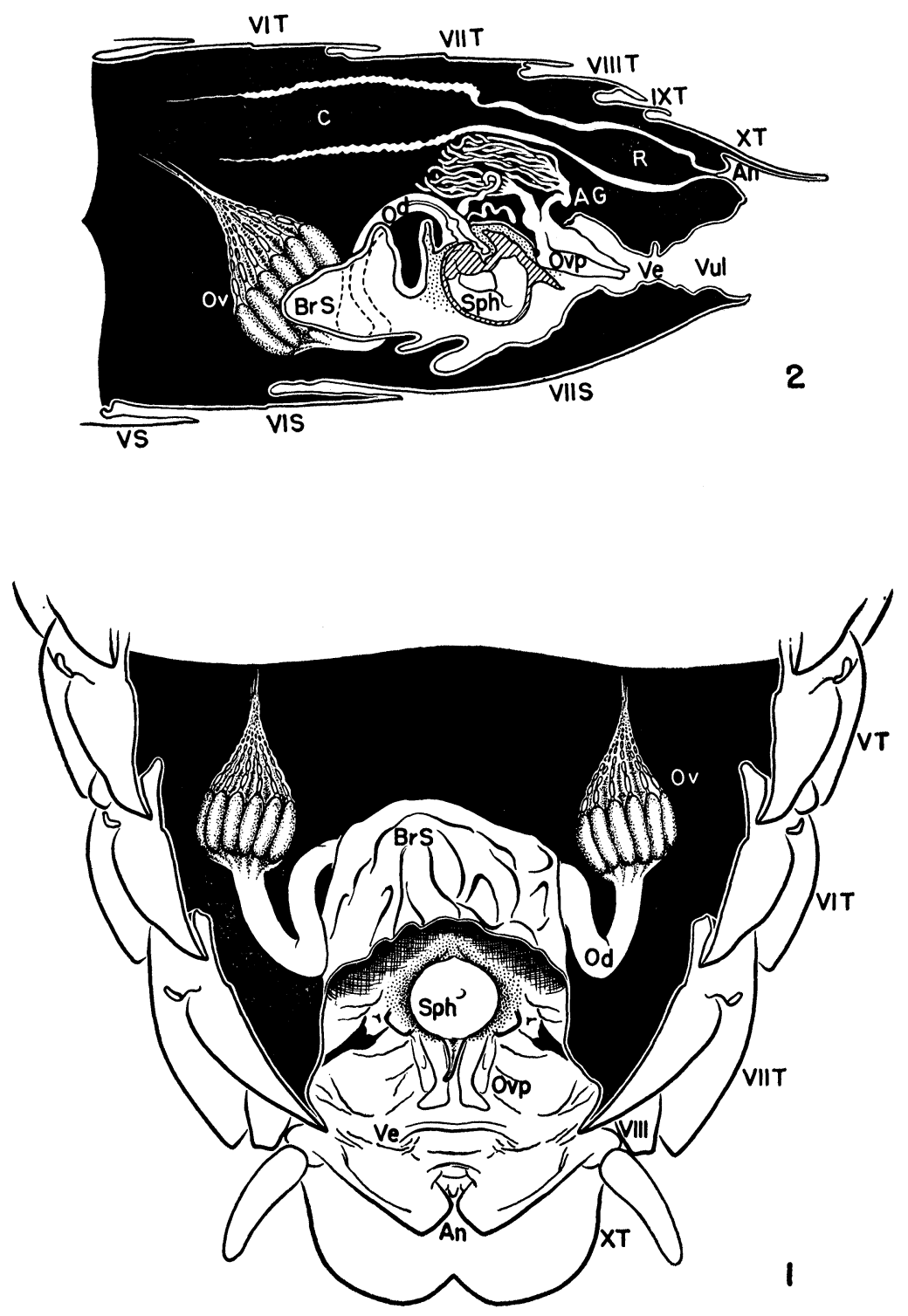

Nutting - Blaberus CRANIIfERA 
would certainly be unnecessary, if not actually impractical here.

One of the largest oöthecae I have seen contained 45 eggs and measured $8 \times 35 \mathrm{~mm}$., while an unusually small one containing 23, probably from an old female, measured $4 \mathrm{x}$ $16 \mathrm{~mm}$. The average number of eggs found in 14 oöthecae was 36.4. Saupe (1929) gave an average of 23.25 eggs for 8 oöthecae, ranging from 11 to 38 per oötheca in $B$. fusca. Stewart (1925) reported an oötheca $1 / 4, \times 11 / 2$ inches containing $44 \mathrm{eggs}$ from a specimen of B. cubensis Saussure. (Rehn and Hebard (1927) refer this species to B. discoidalis Serville.) Two oöthecae of the Central American $B$. trapezoideus Burm. measured $7 \times 35$ and $4.5 \times 31 \mathrm{~mm}$., and contained 40 and $41 \mathrm{eggs}$ respectively. Diploptera, which has been more thoroughly studied than any of the viviparous roaches, exhibits a pseudoplacental type of viviparity and forms an oötheca normally containing but 12 eggs. All other known viviparous roaches produce many more eggs at a time, the numbers per oötheca generally falling within the limits reported for these three species of Blaberus.

While in the brood sac, all the eggs in an oötheca have the micropylar ends directed toward the left. The smallest eggs found in newly formed oöthecae measured 1.7-2.0 x $4.5-5.0 \mathrm{~mm}$.; the largest, shortly before hatching, $2.5 \times 8.2$ $\mathrm{mm}$. In the young germ band stage the pleuropodia resemble short, thick-stalked, immature mushrooms, and project back to the posterior margin of the second abdominal segment. In the chitinized embryo, shortly before they are resorbed, they appear as long, thin-stalked mushrooms extending to the middle of the third abdominal segment. They consist of a base and bulb only; there is no evidence of any pleuropodial extension as found in Diploptera. The eggs contain a large amount of yolk, and a considerable amount is present shortly before hatching. In the absence of any embryological studies on Blaberus, little more can be said concerning embryonic nutrition; it does not seem likely that the mother provides any more than the original yolk.

Many times I have seen females with a newly formed 
oötheca protruding about two-thirds of its length from the brood sac. Some of these females were segregated, and their oöthecae were usually completely returned into the brood sac within a short time. This act apparently signals the completion of an oötheca and the beginning of the incubation period, as has been observed in Gromphadorhina by Chopard (1950). Neither the duration of gestation nor the span of female reproductive life is known for any of the species of Blaberus, although the former may last for more than two months. Females sometimes discard an oötheca; this has occurred most notably after the roaches have been disturbed and handled during cage-cleaning. Except in two cases noted below, none of these oöthecae has been known to hatch.

Recently a relatively inactive female was found with about half the length of her oötheca extruded from the brood sac. At least the pro- and mesothorax of each visible embryo were free of the oötheca. The ensuing events of hatching were observed under a low-power dissecting microscope. All of these embryos were rapidly swallowing air, and the bubbles could easily be seen passing through the head capsule into the enlarging crop. Within 2 or 3 minutes the embryonic cuticle on one individual had split; after 60 to 90 seconds, with some side to side struggling, it was free. Although the abdominal movements of the female indicated that she was trying to expel the oötheca, she was unable to extrude more than three-fourths of its length. I therefore removed the egg case, and within 10 minutes all but four unfertile eggs had hatched.

On becoming free the embryos gradually stopped swallowing air; at this point they were cylindrical and about $10 \mathrm{~mm}$. long. They began telescoping their abdominal segments and within a few seconds they had assumed a flattened roach-like appearance measuring about $7 \mathrm{~mm}$. long. The air is probably expelled through the mouth. The young roaches do not leave the mother but swarm over the oötheca practically consuming it in a short time. Saupe (1929) suspected the mother of devouring the oöthecal remains. A degree of maternal solicitude is exhibited by this roach, for many times I have observed the female to remain 
motionless for an hour or more with her unpigmented brood clustered around and beneath her body. The nymphs are completely pigmented in about 6 hours. I have recorded the next molt as occurring within 15 to 36 days for four different broods.

Although deposited oöthecae generally do not hatch, a mature one, picked up two days after the cage had been cleaned, did hatch after considerable handling. While examining another oötheca six days after its deposition, it was noted that the embryos were swallowing air. Slight pressure on the oötheca while held between the fingers finally resulted in the successful hatching of 14 normal nymphs. Two more nymphs were obtained from this same oötheca upon considerable manipulation ten days after its deposition. On numerous other occasions mature oöthecae have been kept in humid petri dishes for two or three weeks without hatching. The hearts of these embryos continued beating until they finally died from mold or desiccation. These observations strongly suggest that the pressure exerted by the female on the oötheca during extrusion supplies the necessary hatching stimulus. Unless some such stimulus is applied to initiate the air-swallowing, mature embryos remain helplessly encased until death.

The fine line separating ovoviviparity from viviparity seems to be whether or not the embryos hatch before deposition. By strict definition, this single reported observation on the birth of Blaberus nymphs would qualify it as an ovoviviparous insect. Many more observations would be required to determine whether the female generally retains the oötheca while the majority of the embryos hatch; it appears to me quite impossible for the event to take place within the confines of the brood sac itself. Although this categorizing is relatively unimportant, the features which place this fine laboratory insect between the more common oviparous roaches and the viviparous Diploptera are worth noting.

The ovarioles have not been reduced in number (16 to 23 per ovary as opposed to 6 in Diploptera), and the accessory glands are not as highly modified as in Diploptera. Even though each oötheca contains a large number of eggs, 
the period between oöthecae may be measured in weeks rather than in days as in Periplaneta (Gould and Deay, 1940). The brood sac is very large, and the development of the genital pouch approaches that of Diploptera. Lastly, the oötheca is soft, thin, and open, and is retained in the brood sac until hatching. In summary, the major modifications toward viviparity in Blaberus have occurred in the mother and not in the embryo.

Chopard, L.

\section{BIBLIOGRAPHY}

1950. Sur l'anatomie et la développement d'une blatte vivipare. Proc. 8th Int. Cong. Ent. Stockholm, 218-222.

Gould, G. E. and H. O. Deay

1940. The biology of six species of cockroaches which inhabit buildings. Purdue Univ. Agric. Exp. Sta. Bull. 451, 31 pp.

Gupta, P. D.

1947. On copulation and insemination in the cockroach Periplaneta americana (Linn.). Proc. Nat. Inst. Sci. India, 13:65-71.

HAGAN, H. R.

1941. The general morphology of the female reproductive system of a viviparous roach, Diploptera dytiscoides (Serv.). Psyche, 48:1-9.

1951. Embryology of the viviparous insects. New York, Ronald Press. $472+$ xiv pp.

HOLMGREN, N.

1903. Ueber vivipare Insecten. Zool. Jahrb. Abt. Syst., 19: 431-468.

KHALIFA, A.

1950. Spermatophore production in Blattella germanica L. (Orthoptera:Blattidae). Proc. Roy. Ent. Soc. London, 25A:53-61.

LAwson, F. A.

1951. Structural features of the oöthecae of certain species of cockroaches (Blattidae). Ann. Ent. Soc. Amer., 44:269-285.

QADRI, M. A. H.

1938. The life-history and growth of the cockroach Blatta orientalis Linn. Bull. Ent. Res., 29:263-276.

REHN, J. A. G. and M. HeBARD

1927. The Orthoptera of the West Indies: Blattidae. Bull. Amer. Mus. Nat. Hist., 54:pp.257-262.

Roth, L. M. and E. R. WILLIS

1952. A study of cockroach behavior. Amer. Mid. Nat., 47:66-129. 
SAUPE, R.

1929. Zur Kenntnis der Lebensweise der Riesenschabe Blabera fusca Brunner und der Gewächshausschabe Pycnoscelus surinamensis L. Zeitschr. f. angew. Ent., 14:461-500.

Stewart, A. M.

1925. Blabera cubensis (Orthoptera) and its oötheca. Entomologist, 58:57-58.

VAN WYK, L. E.

1952. The morphology and histology of the genital organs of Leucophaea maderae (Fabr.) (Blattidae, Orthoptera). J. Ent. Soc. S. Africa, 15:1-62.

ZaBINSKI, J.

1933. Fonctionnement des différentes parties des appareils copulateurs chitinés males et femelles de la Blatte (Periplaneta orientalis L.). C. R. Soc. Biol., 112:598-602.

Nemestrinidae (Diptera) OF IOWA AND Missouri. A small collection recently sent by $\mathrm{Mr}$. Jean L. Laffoon, at Iowa State College, contains a male of Neorhynchocephalus sackenii (Williston) collected at Sioux City, Woodbury Co., Iowa, June 10, 1949, by J. A. Slater and J. L. Laffoon. It was taken immediately above the mouth of the Sioux River, on top of the loess hills which border the Missouri River in western Iowa. Mr. Laffoon points out to me that this area contains some plants and animals ordinarily found only farther west. It is the first record for any of the Nemestrinidae in Iowa. Specimens of N. sackenii were also collected at Washington University Farm, 7 miles southwest of Clarksville, Pike Co., Missouri, by Mr. Robert A. Dietz, of the University of Tennessee. N. sackenii is now recorded from British Columbia and the states of Washington, Oregon, Montana, California, Idaho, Wyoming, Utah, Arizona, Colorado, New Mexico, Kansas, Oklahoma, Arkansas, Missouri, Iowa, Michigan, and Illinois. I have seen specimens from Huachuca Canyon, Cochise Co., Arizona, August 17, 1950 (R. L. Langston). It is remarkable that there are as yet no records from Mexico. - J. BequaERT, Museum of Comparative Zoology, Cambridge. 

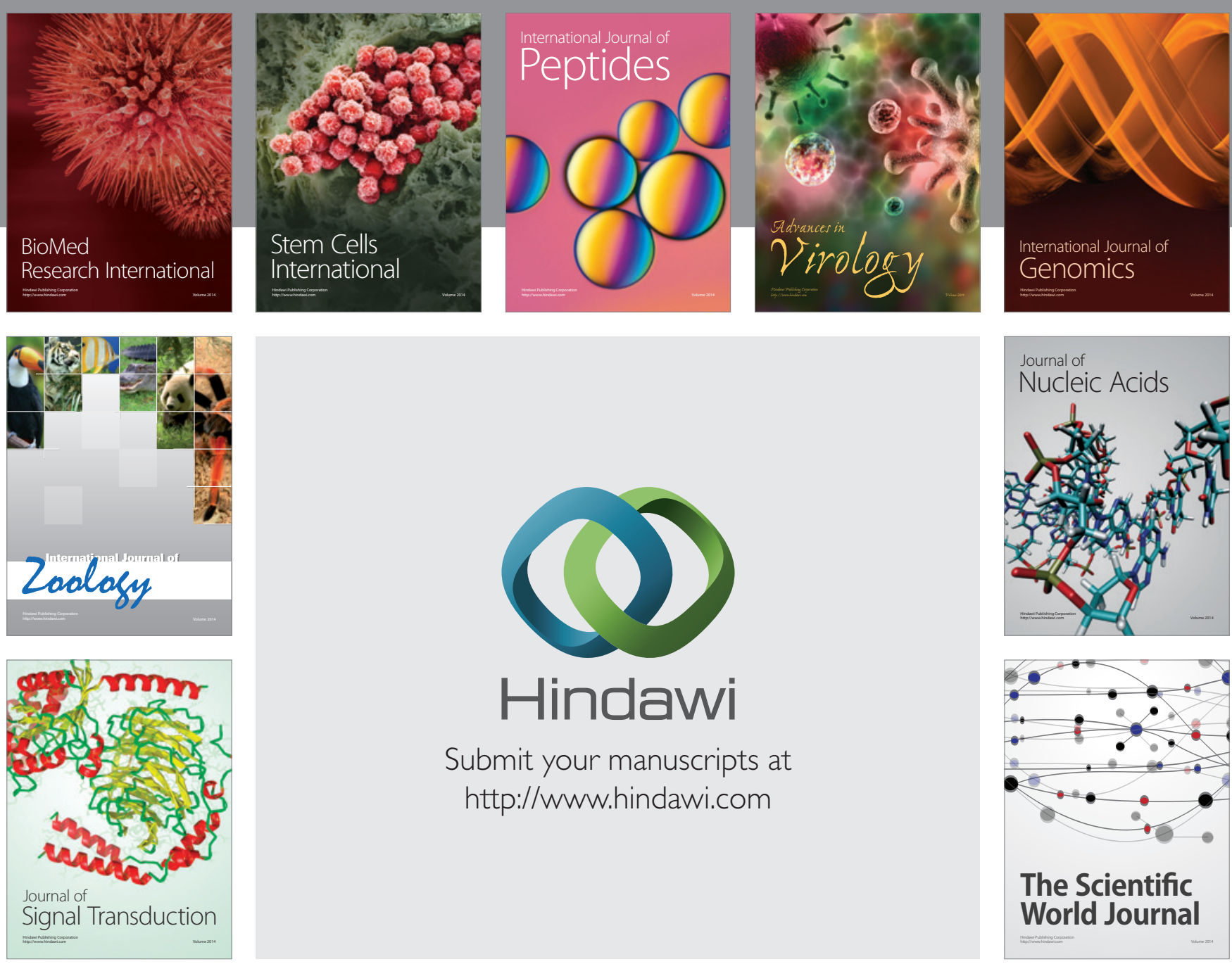

Submit your manuscripts at

http://www.hindawi.com
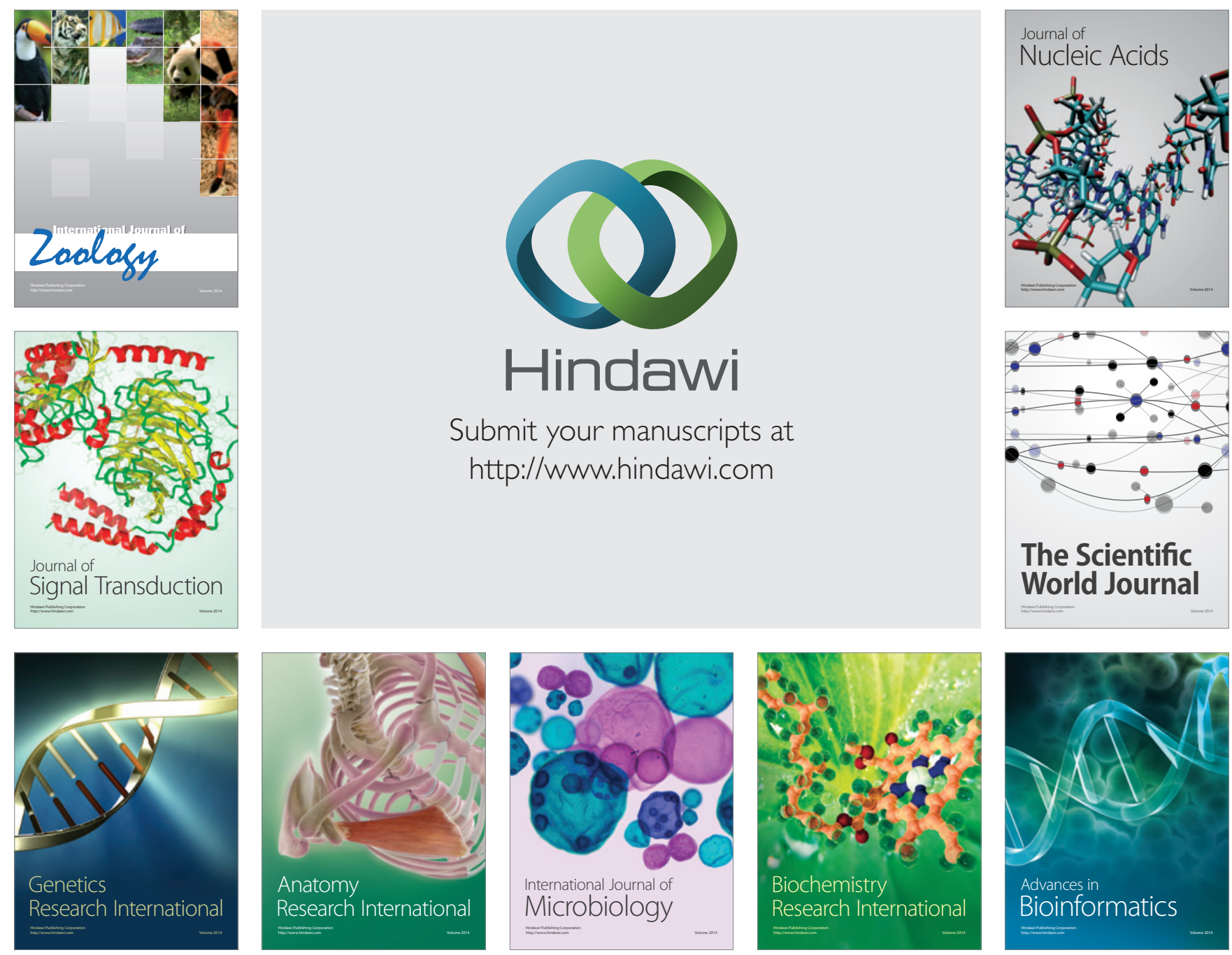

The Scientific World Journal
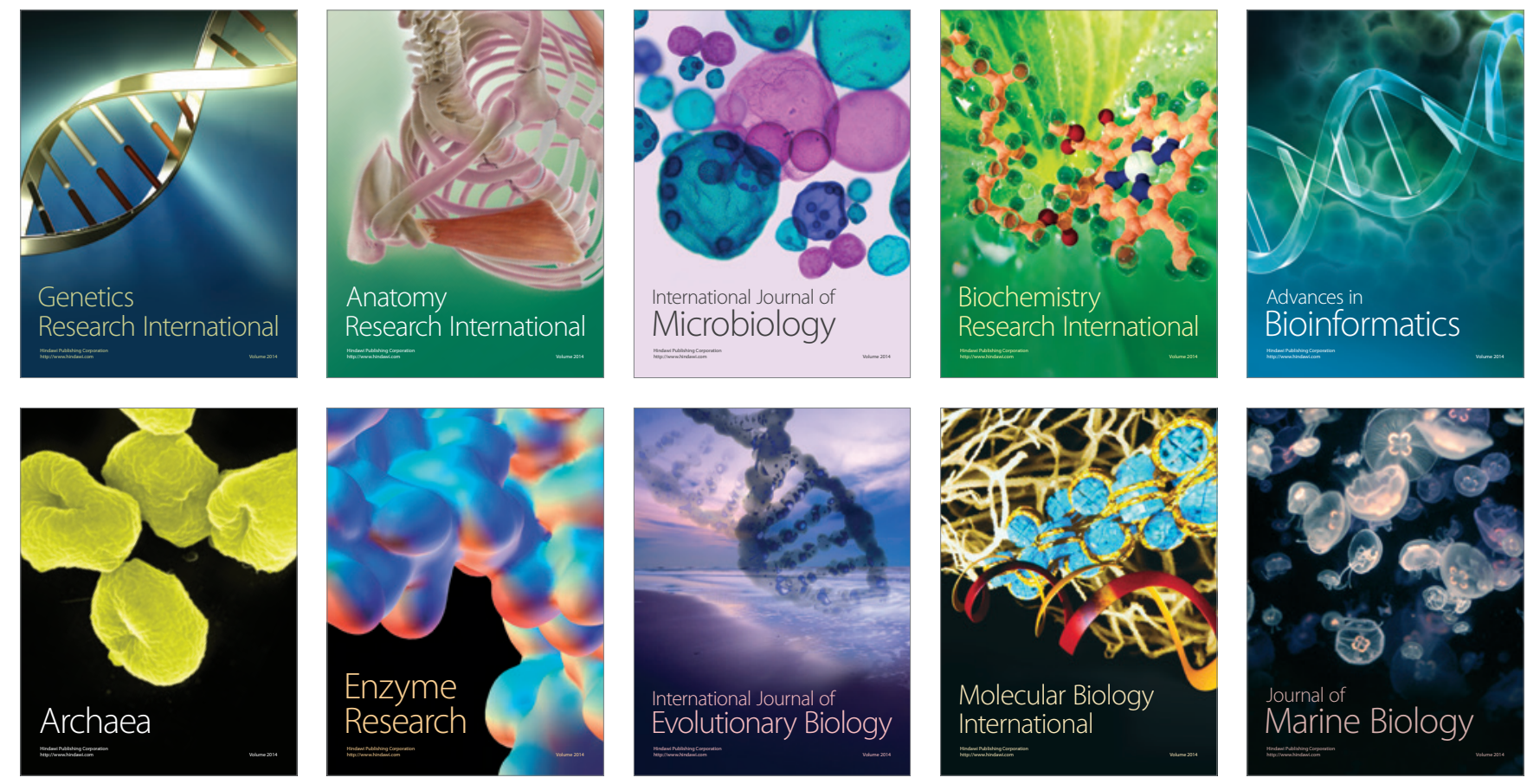